Article

\title{
On the Prevention of Avoidable Food Waste from Domestic Households
}

\author{
Peter J. Shaw *, Matthew M. Smith and Ian D. Williams it \\ Centre for Environmental Science, University of Southampton, Southampton SO17 1BJ, UK; \\ matthew@issafe.co.uk (M.M.S.); I.D.Williams@soton.ac.uk (I.D.W.) \\ * Correspondence: P.J.Shaw@soton.ac.uk; Tel.: +44-(0)2380-595867
}

Received: 28 February 2018; Accepted: 23 May 2018; Published: 1 June 2018

\begin{abstract}
Unconsumed food impacts on the environment via the wasteful use of resources in its production and via its disposal. Householders would ideally only generate food waste that is not considered edible (unavoidable food waste) and the disposal of edible food (avoidable food waste) would be prevented, mitigating both the environmental impacts of food waste and reducing consumers' wasted expenditure on uneaten food. This study aimed to elucidate if and how householders' food waste behaviour might be changed via interventions in the form of a leaflet highlighting the impacts of avoidable food waste. The composition of avoidable food waste set out for kerbside collection was assessed in relation to interventions intended to reduce avoidable food waste and in relation to households' economic status. Two parallel interventions were tested, setting out to householders the impacts of avoidable food waste on (1) the environment, and (2) personal finances. Avoidable food waste set out by affluent and low income households, considered in terms of total weight, life-cycle stage and product group, did not change significantly after delivery of either leaflet. Neither of the interventions tested had a discernible impact on the quantity and composition of avoidable food waste in these terms. We propose that initiatives to reduce food waste may be more successful if focused on positive actions to improve householders' efficiency in their food use, directed by insight provided by analysis of avoidable food waste within product groups and in relation to life-cycle stage.
\end{abstract}

Keywords: food waste; household; waste prevention; behaviour change

PACS: J0101

\section{Introduction}

Food waste is a recognized and global problem. Estimates indicate that a large proportion of the food produced globally for human consumption is not consumed as intended [1,2], and levels of food waste can rise markedly and rapidly [3]. The provision of food for human consumption is resource-intensive throughout the food supply chain (FSC) and through all life-cycle stages [4-7], impacting the environment via use of freshwater [3], land [6], and fertiliser [6]. Post-harvest, losses and waste occur throughout the entire food system (e.g., storage, processing, distribution, consumption [8]) and may account for around a quarter of global cropland, freshwater and fertilizer use [6]; the use of fossil fuels is also wasted [3]. The wastage of unconsumed but edible food also has the potential to underpin food security in the face of rising global population [8]. Moreover, the economic costs of food waste to the consumer are considerable [9]; it was estimated that in 2015 food with a retail value of $£ 13$ billion was thrown away in the UK alone [10]. Prevention of food waste is thus clearly a desirable ambition in many regards [11], not least via contributing to alleviation of demands for and pressure on food production [12]. The reduction or elimination of food waste could provide economic, 
social and environmental benefits, principally through more efficient resource utilization, but there remain significant, cross-sector challenges that must be met if progress is to be made [8-10]. Prior research $[13,14]$ has highlighted the complexities and challenges in this regard $[14,15]$.

Losses and waste associated with consumers are a particular concern [16], notably at household level $[13,17]$ at which "residential behaviours" are critical [15]. Estimates have suggested that around half the losses across the FSC might be attributed to householders, in Switzerland [4] and across EU member states [18], for example. Much research in the field of food waste management has ensued, including "end of pipe" solutions focusing on valorisation of food waste [19] using, for example, anaerobic digestion, composting or incineration [20-22]. Established technologies to gain value from waste food, however, are not without environmental impacts $[5,20,21]$ and do not necessarily offer optimal solutions for the "food waste problem". Selection of food waste treatment methods has implications for their associated impacts [20]. In terms of global warming potential, for example, prevention of avoidable food waste is preferable to incineration or anaerobic digestion [23]. Research on food waste prevention per se has tended to focus upon assessing food waste composition as a means to establish its nature and extent as a problem [24,25] but with arguably too little focus on finding solutions [18]. An important distinction has thereby been recognized [24,25]: to a first approximation food waste comprises either "avoidable" components (e.g., consumable food that is discarded) or "unavoidable" components (e.g., inedible peels and bones). The avoidable component of household food waste is substantial. Estimates indicate, for example, that avoidable food waste accounts for ca. 35\% of total household food waste in Sweden [20] and ca. 56\% in Denmark [25]. The decision regarding whether food waste is avoidable or unavoidable [24] and /or "possibly avoidable" [26] can also be influenced by the attitudes and perceptions of an individual [26]. Moreover, analysis of the composition of food waste has highlighted the considerable potential for reducing avoidable food waste, notably where food availability is high. In the UK, for example, it has been estimated that up to ca. $60 \%$ of food waste is avoidable; this fraction has constituted up to ca. 4.4 million tonnes per year [27].

The potential benefits of preventing avoidable food waste are clearly evident and are arguably more desirable than the benefits of valorisation of food waste [23] and preferable in relation to the principles and philosophy of the waste hierarchy in the context of the FSC "from farm to fork" [28]. Any policies and practices intended to achieve positive change, however, are most likely to be effective if evidence-based. In this regard, the distinction between avoidable and unavoidable food waste is highly instructive. If data available relate only to the total weight or volume of all food waste as disposed of by householders, for example, there is no indication as to the actual quantity of potentially-edible but discarded food (avoidable). Analysis of avoidable food waste when disposed of provides insight into the nature of consumers' habits and practices. Disposal of food items that have not been consumed at all, for example, may be associated with different causal factors than would disposal of "plate waste" leftovers [24]. In order to decrease levels of food waste, we propose that further evidence is needed appertaining to: (1) the quantity and composition of avoidable food waste; and (2) whether and how favourable change can be made in terms of behaviour(s) leading to the avoidable food waste.

With regard to changing the behaviour of those who generate avoidable food waste, information is needed regarding how interventions to modify behaviour might be best targeted [18]. Two specific facets need to be considered. First, discarding unconsumed but edible food has both financial impacts upon consumers (i.e., expenditure without benefit) and broad-scale environmental impacts (i.e., associated with food production and disposal of food waste). Whether there is potential to stimulate or enhance avoidable food waste prevention by alerting consumers to the financial or environmental impacts of food waste remains to be elucidated. The provision of direct economic benefits to consumers is a potential incentive for the prevention of avoidable food [11]. At the same time, concern for the environment and its protection is known to be a key driver of individuals' behaviour with regard to activities with an environmental impact or context [29]. With respect to food waste specifically, doubt has been expressed as to the existence of connections in the minds of individuals between food 
waste and related environmental issues [18]. Secondly, the potential to raise awareness of economic or environmental impacts of food waste as a means to increase food waste prevention needs to be evaluated in the context of financial income, the relationship between household income being known to be a potential if equivocal influence on household food waste generation [18]. The income of a consumer or household may potentially influence their behaviour in terms of food waste generation and response(s) to behaviour change interventions highlighting either economic or environmental benefits of food waste prevention. As has been previously noted, "financial attitudes" may lead to an individual's intention to avoid food waste [13]. Moreover, saving money may well be a stronger motivator of individuals' actions than environmental concerns [18]; people with lower income may spend a higher proportion of their income on food than do those with higher incomes [11] and, arguably, have more to gain by the economic benefits associated with avoidable food waste prevention.

The purpose of this study is thus to contribute evidence to guide policy, initiatives and actions intended to prevent avoidable food waste with focus on persuasion of individual consumers through awareness campaigns [18]. There is value in prototyping and testing interventions that aim to reduce household food waste; written communication is one form of intervention that merits elucidation [18]. This study seeks therefore to determine the potential for householders' behaviour to be altered by means of an information-based intervention such that better prevention of avoidable food waste can be achieved.

\section{Materials and Methods}

\subsection{Study Area}

The study examined food waste within the Borough of Eastleigh in southern England. In the 2011 census Eastleigh had a population of 125,000 in 52,000 households and over $99 \%$ of Borough residents lived in a household as opposed to a communal home [30]. Eastleigh's dwellings comprise $34 \%$ detached houses and bungalows, $28 \%$ semi-detached houses and bungalows, $22 \%$ terraced dwellings, and $14 \%$ flats or maisonettes [30]. Eastleigh Borough has a well-established ( $>20$ years) multi-material kerbside collection system for household waste comprising alternate weekly property-close collections using a wheeled bin system for (1) dry recyclable materials (paper, newspapers \& magazines, card, aerosol cans, plastic bottles and cans) and (2) residual waste. Kitchen (food) waste is collected within the property using a "kitchen caddy", the contents of which are transferred to a larger container that is set out at the kerbside and collected weekly on the same day as wheeled bins. Glass and batteries are collected at monthly intervals from the kerbside in a box. A garden waste collection service is also available, a cost for which must be paid for by the householder. Eastleigh thus has mature and well-established kerbside recycling facilities. Householders have been supplied with materials to promote recycling and inform them regarding the operation and use of the kerbside collections. The recycling rate is routinely above $40 \%$. Interventions intended to enhance food waste prevention (Section 2.2) should, in principle, build upon the existing and well-established contributions of householders to waste management via their recycling activities.

\subsection{Experimental Design}

To assess the potential of interventions to reduce avoidable food waste, householders' responses to interventions were determined via an in situ trial using directly-measured food waste composition data (Section 2.3). Trials were carried out using a variant of the "before-after-control-impact" (BACI) experimental design that is more commonly applied in ecological research [31]. The experimental design aligns with the purpose of the work re: "prototyping and testing" of interventions [18]. The field trail was thus orientated to elucidation of the short-term impacts of the interventions. Longer-term impacts (e.g., alteration of routines and/or habits) were not determined. The food waste that householders set out was analysed over two consecutive weekly collections, after which a leaflet was delivered to each household, encouraging reduction of avoidable food waste. Leaflets 
were delivered within two days of the second weekly set-out. Three treatment groups were assessed contemporaneously; two groups received a leaflet highlighting either the economic costs or environmental impacts of avoidable food waste and a third group acted as an experimental control (Table 1). Householders' food waste was then collected and analysed over the subsequent two consecutive weekly set-outs. Given the observed variability of food waste composition [13,25], observations over a longer period would clearly be desirable; in this instance the duration of observations was limited by available resources. The in situ field-scale trials thereby assessed the potential of contrasting interventions to reduce avoidable food waste with regard to (1) the influence of householders' economic (income) status, and (2) the influence of message (i.e., emphasis on the economic or environmental impacts of avoidable food waste) (Table 1).

Table 1. Experimental design for in situ field-scale trials of interventions to induce food waste prevention behaviour. Numbers in parentheses indicate sample size (households) in each treatment group.

\begin{tabular}{ccc}
\hline Income Status & Treatment Group & Treatment \\
\hline \multirow{2}{*}{ Affluent (30) } & Control (10) & No intervention \\
& Treatment 1 (10) & Leaflet: financial costs of food waste \\
& Treatment 2(10) & Leaflet: environmental impacts of food waste \\
\hline \multirow{2}{*}{ Low income (30) } & Control (10) & No intervention \\
& Treatment 1 (10) & Leaflet: financial costs of food waste \\
& Treatment 2(10) & Leaflet: environmental impacts of food waste \\
\hline
\end{tabular}

Trials focused on two groups of households that differed in terms of their residents' economic status. Specific locations for these groups were identified using Mosaic classifications supplied by Eastleigh Borough Council. The two areas selected aligned with "Career Professionals Living in Sought-After Locations" and "Low Income Families Living in Estate-Based Social Housing". Henceforward we refer to these groups as "affluent" and "low income" households, respectively.

Food waste was collected from 60 households (Table 1). During the first survey, the first 30 households in each of the two survey areas that had set out a food waste container were selected for monitoring. When set out for collection, containers were collected from these same households during the three subsequent surveys. Whilst an entirely random selection of households would be preferred, sampling was in this instance constrained by logistical considerations. The households in both affluent and low income areas were split into three randomised sub-groups of 10 households, comprising a control and two treatment groups (Table 1). The interventions comprised one of two leaflets, emphasizing either the environmental impacts or the financial costs of avoidable food waste [32]. The control group did not receive any intervention or information as part of the field trial.

\subsection{Food Waste Sample Collection and Analysis}

Collection of food waste samples took place over four weeks (8 July to 2 August) in 2012. Samples comprised only items of food waste set out in kerbside-collected containers; items placed elsewhere (e.g., residual waste bins and/or used for home composting) were not determined. Samples were obtained the evening before the food waste collection day in all cases. Samples were sorted following an established method [24] with amendments: noodles and couscous were included with "pasta and rice", and the unclassifiable remainder was not classified as "avoidable". Weights of unclassifiable food waste were omitted from analyses. Samples were sorted and weighed within two days of collection [33] to permit the fullest level of identification of the material. Samples were initially sorted into unavoidable and avoidable food waste (Table 2). Unavoidable food waste was weighed but not classified further. The avoidable food waste was separated into individual items and classified according to: name of product; product category, life-cycle stage and net weight excluding packaging. Although "possibly avoidable" food waste has also been proposed and applied as a further category [26], the present work was guided by the classification system as presented (Table 2). Whilst this approach does 
not take into account variance in what is considered "edible", classification was carried out in a consistent if imperfect manner that is well-established and has, arguably, proven to be duly effective and informative in other food waste research [23-25,27]. No sorting or sieving was undertaken prior to the food waste audit. The contents of individual food waste containers set out for collection were not pooled or aggregated, but audited on a household-specific basis.

Table 2. The food waste classification system employed in the present study. Adapted from Lebersorger \& Schneider [24].

\begin{tabular}{ccl}
\hline Avoidable/Unavoidable & Life-Cycle Stage & \multicolumn{1}{c}{ Packaging } \\
\hline Unavoidable & $\begin{array}{c}\text { Preparation residues/some } \\
\text { leftovers (e.g., bones) }\end{array}$ & Not applicable \\
\hline Avoidable & Edible leftovers & Not applicable \\
\hline Avoidable & Whole unused & $\begin{array}{l}\text { (i) In original, unopened sales packaging } \\
\text { (ii) Others (not in original packaging) }\end{array}$ \\
\hline Avoidable & Part consumed & $\begin{array}{l}\text { (i) In original sales packaging } \\
\text { (ii) Others (not in original packaging) }\end{array}$ \\
\hline- & Unclassifiable remainder & - \\
\hline
\end{tabular}

Non-biodegradable food packaging is not collected in Eastleigh's food waste kerbside collection scheme; information relating to quantities of food packaging was not recorded in the present study. For food items discarded with packaging, records were made—as far as possible—of gross weight (including any packaging), brand name, current fill, best-before date, use-by date, date of packaging, price of product, and original package weight. All weights were recorded to the nearest $0.1 \mathrm{~g}$.

\subsection{Data Analysis}

Data were tested for normality and equal variance. In all cases, data failed normality and/or equal variance tests were subjected to non-parametric statistical tests. Differences between avoidable food waste arising (total, by product category and life-cycle stage) before and after the interventions (Table 1) were tested using the Mann-Witney U test combined with a multiple pairwise comparison test (Dunn's method).

\section{Results}

\subsection{Impacts of Interventions on Total Avoidable Food Waste Arisings and Composition by Life Cycle Stage}

In terms of the total avoidable food waste set out by householders, differences were apparent before and after the interventions; average weekly weight changes ranged from $-2 \%$ to $+42 \%$ (Table 3 ). Most of the changes indicated an increase in the average weekly weight of avoidable food waste after the interventions (Table 3). There was, however, no statistically significant difference in the weekly total weight of avoidable food waste before and after the leaflet intervention (Table 1) for households receiving a leaflet emphasizing either the financial or the environmental impacts of avoidable food waste (Table 3). There was thus no evidence of a meaningful response amongst those households monitored (Table 3) to either type of intervention (Table 1) in terms of the total weekly weights of avoidable food waste set out by the householders observed in this study.

The composition of food waste samples collected was also considered in terms of life-cycle stage (Table 3). Avoidable food waste set out for collection comprised broadly similar quantities of part-consumed items, leftovers, and whole-unused items. The small proportions of items set out for collection still in their original packaging ( $0.4 \%$ to $1.4 \%$ by weight) demonstrated a high level of compliance with the kerbside collection scheme's requirement for excluding non-biodegradable packaging from kitchen waste. Although differences were evident in the weekly weights of avoidable 
food waste in the three life cycle stages (Table 3) before and after either leaflet intervention (Table 1), none of the differences was statistically significant. There was thus no evidence of a meaningful or consistent response of householders to the leaflet intervention (Table 3) in this regard.

Table 3. Average weekly set-outs of total avoidable food waste and quantities within life-cycle stages (Table 2) observed in trials of behaviour change interventions (Table 1). Data shown are for all food waste containers set out for kerbside collection over a two week period pre- or post-intervention in each treatment group $(N)$. Whole-unused and part-consumed items include those with and without original sales packaging (see Table 2). Change indicates the percentage change from pre- to post-intervention average weekly weights.

\begin{tabular}{|c|c|c|c|c|c|c|c|}
\hline $\begin{array}{l}\text { Income } \\
\text { Status }\end{array}$ & Treatment Group ${ }^{1}$ & $\begin{array}{c}\text { Pre- or } \\
\text { Post-Intervention }\end{array}$ & $N$ & Total $^{2}$ & Whole-Unused ${ }^{2}$ & Part-Consumed ${ }^{2}$ & Leftovers $^{2}$ \\
\hline \multirow{9}{*}{ Affluent } & \multirow{3}{*}{ Control } & Pre- & 20 & $514 \pm 76$ & $158 \pm 59$ & $147 \pm 30$ & $192 \pm 43$ \\
\hline & & Post- & 19 & $518 \pm 139$ & $122 \pm 52$ & $141 \pm 58$ & $215 \pm 68$ \\
\hline & & Change & & $+1 \%$ & $-23 \%$ & $-4 \%$ & $+12 \%$ \\
\hline & \multirow{3}{*}{$\begin{array}{l}\text { Economic costs } \\
\text { intervention }\end{array}$} & Pre- & 18 & $326 \pm 64$ & $35 \pm 27$ & $124 \pm 25$ & $163 \pm 53$ \\
\hline & & Post- & 18 & $397 \pm 133$ & $135 \pm 61$ & $191 \pm 64$ & $69 \pm 26$ \\
\hline & & Change & & $+22 \%$ & $+286 \%$ & $+54 \%$ & $-58 \%$ \\
\hline & \multirow{3}{*}{$\begin{array}{c}\text { Environmental } \\
\text { impacts intervention }\end{array}$} & Pre- & 19 & $343 \pm 76$ & $118 \pm 66$ & $177 \pm 51$ & $46 \pm 17$ \\
\hline & & Post- & 17 & $486 \pm 91$ & $138 \pm 45$ & $161 \pm 49$ & $125 \pm 48$ \\
\hline & & Change & & $+42 \%$ & $+17 \%$ & $-9 \%$ & $+172 \%$ \\
\hline \multirow{9}{*}{$\begin{array}{l}\text { Low } \\
\text { income }\end{array}$} & \multirow{3}{*}{ Control } & Pre- & 17 & $583 \pm 108$ & $98 \pm 40$ & $182 \pm 57$ & $284 \pm 110$ \\
\hline & & Post- & 12 & $773 \pm 101$ & $233 \pm 99$ & $299 \pm 95$ & $189 \pm 63$ \\
\hline & & Change & & $+33 \%$ & $+138 \%$ & $+64 \%$ & $-33 \%$ \\
\hline & \multirow{3}{*}{$\begin{array}{l}\text { Economic costs } \\
\text { intervention }\end{array}$} & Pre- & 18 & $697 \pm 140$ & $253 \pm 95$ & $218 \pm 60$ & $226 \pm 61$ \\
\hline & & Post- & 14 & $684 \pm 128$ & $112 \pm 51$ & $298 \pm 99$ & $263 \pm 59$ \\
\hline & & Change & & $-2 \%$ & $-56 \%$ & $+37 \%$ & $+16 \%$ \\
\hline & \multirow{3}{*}{$\begin{array}{c}\text { Environmental } \\
\text { impacts intervention }\end{array}$} & Pre- & 17 & $610 \pm 90$ & $182 \pm 63$ & $239 \pm 44$ & $189 \pm 74$ \\
\hline & & Post- & 13 & $771 \pm 170$ & $94 \pm 37$ & $542 \pm 181$ & $119 \pm 34$ \\
\hline & & Change & & $+26 \%$ & $-48 \%$ & $+127 \%$ & $-37 \%$ \\
\hline
\end{tabular}

${ }^{1}$ See Table $2 .{ }^{2}$ g per household per week \pm 1 standard error.

\subsection{Impacts of Interventions on Avoidable Food Waste Composition by Product Category}

Of the product categories of avoidable food waste audited, four products (fruit, vegetables, bread, and prepared meals) each commonly accounted for ca. $15-25 \%$ of the total by weight; all other product categories each accounted for a minor fraction (less than ca. $4 \%$ by weight). Subsequent analysis thus focused on the four most prevalent product categories.

When considered in terms of weekly weights of avoidable food waste in product categories, differences were again evident between householders' set-outs before and after the interventions. Average weekly weight changes from before to after the intervention (Table1) ranged from $-59 \%$ to $+155 \%$ for fruit, $-56 \%$ to $+166 \%$ for vegetables, $-65 \%$ to $+41 \%$ for bread, and $-96 \%$ to $+357 \%$ for prepared meals (Table 4).

When tested statistically, there was found to be no significant difference in the weekly total weight of avoidable fruit, vegetables, bread and prepared meal food waste before and after the leaflet intervention (Table 4) for households receiving either a leaflet emphasizing the financial or a leaflet the environmental impacts of avoidable food waste. There was thus no evidence of a meaningful response amongst those households monitored (Table 4) to any of the interventions tested (Table 1). 
Table 4. Average weekly set-outs of avoidable food waste attributable to the four most prominent product categories observed in trials of behaviour change interventions (Table 1). Data shown are for all food waste containers set out for kerbside collection over a two week period pre- or post-intervention in each treatment group $(N)$. Change indicates the percentage change from pre- to post-intervention average weekly weights.

\begin{tabular}{|c|c|c|c|c|c|c|c|}
\hline $\begin{array}{l}\text { Income } \\
\text { Status }\end{array}$ & Treatment Group ${ }^{1}$ & $\begin{array}{c}\text { Pre- or } \\
\text { Post-Intervention }\end{array}$ & $N$ & Fruit $^{2}$ & Vegetables $^{2}$ & Bread $^{2}$ & Prepared Meal $^{2}$ \\
\hline \multirow{8}{*}{ Affluent } & \multirow[b]{2}{*}{ Control } & Pre- & 20 & $182 \pm 56$ & $80 \pm 39$ & $57 \pm 22$ & $106 \pm 42$ \\
\hline & & $\begin{array}{l}\text { Post- } \\
\text { Change }\end{array}$ & 19 & $\begin{array}{c}74 \pm 23 \\
-59 \%\end{array}$ & $\begin{array}{l}125 \pm 56 \\
+56 \%\end{array}$ & $\begin{array}{c}57 \pm 29 \\
0 \%\end{array}$ & $\begin{array}{c}176 \pm 68 \\
+66 \%\end{array}$ \\
\hline & \multirow{3}{*}{$\begin{array}{l}\text { Economic costs } \\
\text { intervention }\end{array}$} & Pre- & 18 & $74 \pm 29$ & $98 \pm 32$ & $22 \pm 10$ & $44 \pm 23$ \\
\hline & & Post- & 18 & $189 \pm 78$ & $72 \pm 38$ & $30 \pm 14$ & $39 \pm 24$ \\
\hline & & Change & & $+155 \%$ & $-27 \%$ & $+36 \%$ & $-11 \%$ \\
\hline & \multirow{3}{*}{$\begin{array}{l}\text { Environmental impacts } \\
\text { intervention }\end{array}$} & Pre- & 19 & $43 \pm 22$ & $114 \pm 65$ & $111 \pm 38$ & $14 \pm 11$ \\
\hline & & Post- & 17 & $105 \pm 40$ & $84 \pm 34$ & $107 \pm 38$ & $64 \pm 43$ \\
\hline & & Change & & $+144 \%$ & $-26 \%$ & $-4 \%$ & $+357 \%$ \\
\hline \multirow{9}{*}{$\begin{array}{l}\text { Low } \\
\text { income }\end{array}$} & \multirow{3}{*}{ Control } & Pre- & 17 & $83 \pm 27$ & $115 \pm 32$ & $515 \pm 58$ & $169 \pm 87$ \\
\hline & & Post- & 12 & $118 \pm 29$ & $306 \pm 130$ & $182 \pm 66$ & $62 \pm 54$ \\
\hline & & Change & & $+42 \%$ & $+166 \%$ & $-65 \%$ & $-28 \%$ \\
\hline & \multirow{3}{*}{$\begin{array}{l}\text { Economic costs } \\
\text { intervention }\end{array}$} & Pre- & 18 & $122 \pm 48$ & $211 \pm 75$ & $109 \pm 51$ & $108 \pm 46$ \\
\hline & & Post- & 14 & $242 \pm 92$ & $170 \pm 92$ & $39 \pm 15$ & $78 \pm 23$ \\
\hline & & Change & & $+98 \%$ & $-19 \%$ & $-64 \%$ & $-28 \%$ \\
\hline & \multirow{3}{*}{$\begin{array}{l}\text { Environmental impacts } \\
\text { intervention }\end{array}$} & Pre- & 17 & $150 \pm 53$ & $135 \pm 32$ & $119 \pm 35$ & $108 \pm 74$ \\
\hline & & Post- & 13 & $361 \pm 152$ & $60 \pm 30$ & $168 \pm 26$ & $4 \pm 4$ \\
\hline & & Change & & $+141 \%$ & $-56 \%$ & $+41 \%$ & $-96 \%$ \\
\hline
\end{tabular}

${ }^{1}$ See Table $2 .{ }^{2}$ g per household per week \pm 1 standard error.

\section{Discussion}

This study has, for the Eastleigh case study, elucidated key facets of householders' behaviour with respect to the avoidable food waste they generate and discard. The field trials of two interventions demonstrated no statistically meaningful impact, whether leaflets emphasized the financial or environmental impacts of avoidable food waste, or were delivered to affluent or low income households (Table 1). Indeed, the lack of differences arising from the intervention negated the need to carry out in full the statistical analyses usually associated with the before-after-control-impact experimental design [31].

This study indicates that neither of the interventions used had a discernible impact on householders' behaviour in relation to food waste in terms of either total avoidable food waste (Table 3), food waste by life-cycle stage (Table 3) or food waste by product (Table 4). In consequence, messages for campaigns or interventions to reduce avoidable food waste in Eastleigh are considered unlikely to make a positive difference if a leaflet-format intervention is used with focus on the negative environmental or financial impacts of food waste (Table 1). Given the complexity and range of factors that are believed to influence food waste behaviour [14], there is a possibility that impacts of these interventions might not be realised until there has been sufficient time to influence householders' actions. Planning and associated food shopping, for example, might well operate on timescales commensurate with a habitual context [14] at which a response to interventions might not be manifest until after longer than two weeks after the intervention itself.

\subsection{Householders' Responses to Behaviour Change Interventions}

The lack of measurable householders' response to the intervention used in the present study may be due to several reasons. Elsewhere in the UK, leaflet campaigns have not resulted in a discernible effect on householders' waste recycling behaviour [34]. Other studies have identified that householders respond better to other forms of intervention such as door-to-door communications [35]. Moreover, with a high level of variation in avoidable food waste arisings, changes in householders' behaviour may well be occluded by the variance of the data, as indicated by the high standard error values relative to 
average weekly food waste arisings (Tables 3 and 4). A longer set of pre- and post-intervention food waste surveys and/or larger sample size [25] may be needed to provide the basis for more meaningful analysis. We note that the high level of variation observed in food waste set-outs influences the outcomes of quantitative and statistical analyses. This high level of variance is a repeated pattern in studies of food waste composition that occurs across a wide range of sampling effort and means $[13,25]$ and will likely continue to present challenges to interpreting such observations. We note additionally that surveys were undertaken of kitchen waste containers collected at the kerbside. These observations do not therefore permit insight to other possible destinations of food waste that may have been precipitated by the leaflet intervention, e.g., home composting or pet feeding.

The observed lack of difference in the responses of householders to interventions stressing financial and environmental impacts of food waste conflicts with the findings of some previous research. In an assessment of deploying financial incentives as a means to enhance use of a kerbside recycling scheme, recycling was deemed more of an altruistic act in which participation was less likely to be motivated by personal gain than by a desire to contribute to the common good [36]. Alignment of householders' actions with altruistic, environmentally-motivated actions may thus be expected [29], but this study suggests a lack of such a response in this instance vis-à-vis the lack of response to the intervention focused upon the environmental impacts of avoidable food waste (Table 1). Likewise, alerting householders to the financial losses associated with avoidable food waste (Table 1) did not evoke an identifiable response. We suggest that this lack of response may be influenced by the magnitude of household-specific financial losses. For the UK, the cost of wasted food to the average household in 2010 was $£ 480$ per year; in the same year the average UK salary was $£ 500$ per week [37]. Although food waste thus typically accounts for ca. one week of an average salary, we note that the typical daily cost of food waste per household is $£ 1.32$, i.e., substantially less than the price of a coffee at a UK high street outlet. Although financial aspects comprise one element of recycling scheme design [38], intrinsic, personal beliefs are broadly considered to motivate participation in household waste recycling $[29,39]$. The potential for financial and/or altruistic factors to stimulate or motivate behaviours aligned with householders' waste management appears not to be manifest in relation to food waste prevention behaviour on the basis of this study. With regard to both interventions tested in this study, the lack of perceived connection of an individual's activity and its consequences may offer an explanation for the observed lack of response, food waste behaviours perhaps being driven by and performed for reasons that are not directly related to waste prevention [14]. Moreover, there is a possibility that the "power" of information as a driver of food waste behaviour is somewhat limited [18].

\subsection{Implications for Food Waste Prevention}

Whilst the observed data question and undermine the value of leaflet-based interventions (Table 1) as means to reduce avoidable food waste (on a short-term basis, at least), observations made nonetheless provide insight that could underpin other initiatives to reduce or prevent avoidable food waste arisings [18]. For those households surveyed, avoidable food waste comprised mainly fruit, vegetables, bread, and prepared meals (Table 4) that were discarded mainly as part-consumed items, whole-unused items, or as leftovers (Table 3). In this regard, the Eastleigh case study aligns closely with other compositional analyses of food waste [24,25]. Elimination of these four predominant product groups (Table 4) via complete consumption could, if achievable, result in a reduction in avoidable food waste of ca. $80 \%$. We suggest, however, that broad campaigns initiated to prompt reduction or prevention of avoidable food waste would likely have the greatest benefit if the focus for such interventions or campaigns were to be duly informed by the analysis of discarded products in relation to their life-cycle stage at the point of disposal.

In this respect, strategies for food waste prevention could potentially be more successful if orientated around the behaviour and influencing factors that led to their disposal [14]. Comparison of quantities of avoidable food waste per product group (Table 4) within the different life-cycle stages 
(Tables 2 and 3) is instructive in this regard. Prepared meals, for example, typically accounted for ca. $100 \mathrm{~g}$ per household per week of avoidable food waste, all of which comprised leftovers in terms of life-cycle stage (Table 2). In contrast, bread products placed in kitchen waste bins contributed a similar quantity to prepared meals but were comprised mainly of part-consumed products. Avoidable food waste comprising fruit and vegetables differed from bread and prepared meals in terms of life-cycle stage, being mainly composed of a mixture of part-consumed and whole-unused items. It may be speculated that part-consumed and whole-unused items (bread, fruit and vegetables; Table 4) could be related to consumers' behaviour in regard to meal planning [19,40], shopping [40], use of leftovers [40] or food storage [24], whilst leftovers may more likely be associated with poor portion control, for example [32]. We note that such factors align with "skills" and "logistics" in relation to food waste behaviour [15]. However, without motivation to act-which may be associated with a complex and inter-related suite of factors [14,18,40-42] — the desire to seek and obtain the appropriate skills and logistics to reduce avoidable food waste is likely low or negligible.

With regard to campaigns and interventions, advice and guidance on "portion and plan" [32] has potential to reduce both unconsumed food (whole-unused or part-consumed) and leftovers (Table 3) by addressing the influence of over-buying food and/or preparing portions that exceed dietary needs or appetite. Such approaches are notable in that reductions of food waste could ensue for all four major food products that are discarded in Eastleigh (Table 4). As noted, the steps and decisions leading to leftovers and part-consumed or whole-unconsumed products differ [43]. In addition to food planning with emphasis on portion size, the provision of recipes intended to reduce avoidable food waste and guidance on storage of foodstuffs [32] can have positive impacts in reducing quantities of unconsumed food or leftovers. We note that a food waste prevention campaign message to "Love Food, Hate Waste" $[32,44]$ expresses a positive view with emphasis on practical actions to use food more effectively and more fully. Such an approach differs markedly to a view focusing on the deleterious financial and environmental impacts of food waste as trialed in the present study (Table 1).

More generally, this study highlights a notable gap in our understanding of householders' waste management behaviours. Much prior research has focused on householders' recycling behaviour as opposed to their waste prevention behaviour; recyclers are not necessarily seen as waste minimisers and those who reduce their waste do not necessarily recycle [45]. Recyclers may not identify waste reduction as the solution to the problems associated with waste in general terms [45].

This study assumed that in focusing on households that are already participating in a multi-material kerbside recycling scheme that includes a voluntary food waste recycling scheme, householders would be well placed to extend their existing behaviour to include waste prevention as well as recycling. Our observations concur with the proposal [45] that there is low potential for behaviour change with regards to waste prevention amongst a group of recyclers: recycling may be a normative behaviour whilst waste prevention is not. As noted, "spillover" effects of recycling into other realms of pro-environmental behaviour is by no means a given and cannot be assumed [42].

\section{Conclusions and Recommendations}

This study has established that, for the case study to hand, leaflet interventions intended to promote reduction of avoidable food waste had no statistically meaningful impact on the avoidable food waste set out for collection by households observed over a short-term field trial. Whether the economic or the environmental impacts of avoidable food waste were highlighted, householders did not respond measurably to the information in leaflets. We conclude that there is likely to be little merit in deploying such leaflets as means to encourage or foster avoidable food waste prevention.

In the light of this observation, interventions to promote prevention of food waste may be well-advised to employ different means to deliver different messages. In this study, leaflets delivered to householders presented to them the reasons why avoidable food prevention is desirable but not how to effect positive change. In this regard, the WRAP "Love Food, Hate Waste" campaign has considerable 
merit in emphasising actions, methods and information aligned with food waste prevention [9] and adopting a wide range of communication and dissemination methods [40].

Moreover, we propose that insight to food waste behaviour may be gained through analysis of food waste products in relation to life-cycle stage could have considerable merit with regard to understanding better the underpinning reasons and factors. If better understanding of why avoidable food waste arises can be achieved, the strategies to prevent would be more suitably informed and likely lead to positive outcomes.

Author Contributions: Matthew M. Smith, Ian D. Williams and Peter J. Shaw conceived and designed the experiments, and analysed and interpreted the data; Matthew M. Smith performed the majority of the field measurements.

Acknowledgments: The authors are grateful for the support of Eastleigh Borough Council during this project and would like to thank Angela Taylor in particular for information and insights into the area of study, and Richard Saunders for encouragement and assistance in the field.

Conflicts of Interest: The authors declare no conflict of interest.

\section{References}

1. Food and Agriculture Organization of the United Nations (FAO). Global Food Losses and Food Waste-Extent, Causes and Prevention; FAO: Rome, Italy, 2011.

2. Institution of Mechanical Engineers (IMechE). Global Food: Waste Not, Want Not; ImechE: London, UK, 2013.

3. Hall, K.D.; Guo, J.; Dore, M.; Crow, C.C. The progressive increase of food waste in America and its environmental impact. PLoS ONE 2009, 4, e7940. [CrossRef] [PubMed]

4. Beretta, C.; Stoessel, F.; Baier, U.; Hellweg, S. Quantifying food losses and the potential for reduction in Switzerland. Waste Manag. 2013, 33, 764-773. [CrossRef] [PubMed]

5. Lundie, S.; Peters, G.M. Life cycle assessment of food waste management options. J. Clean. Prod. 2005, 13, 275-286. [CrossRef]

6. Kummu, M.; de Moel, H.; Porkka, M.; Siebert, S.; Varis, O.; Ward, P.J. Lost food, wasted resources: Global food supply chain losses and their impacts on freshwater, cropland, and fertiliser use. Sci. Total Environ. 2012, 438, 477-489. [CrossRef] [PubMed]

7. Parfitt, J.; Barthel, M.; Macnaughton, S. Food waste within food supply chains: Quantification and potential for change to 2050. Philos. Trans. R. Soc. B 2010, 365, 3065-3081. [CrossRef] [PubMed]

8. Alexander, P.; Brown, C.; Arneth, A.; Finnigan, J.; Moran, D.; Rounsevell, M.D.A. Losses, inefficiencies and waste in the global food system. Agric. Syst. 2017, 153, 190-200. [CrossRef] [PubMed]

9. Waste and Resources Action Programme (WRAP). Solutions to Prevent Household Food Waste. Available online: http:/ /www.wrap.org.uk/content/solutions-prevent-household-food-waste (accessed on 26 February 2018).

10. Quested, T.; Parry, A. Household Food Waste in the UK, 2015. WRAP. January 2017. Available online: http: //www.wrap.org.uk/sites/files/wrap/Household_food_waste_in_the_UK_2015_Report.pdf (accessed on 26 February 2018).

11. Schneider, F.; Lebersorger, S. The challenges of food wastage to European Society. In Proceedings of the 15th European Roundtable on Sustainable Consumption and Production, Bregenz, Austria, 2-4 May 2012.

12. Halloran, A.; Clement, J.; Kornum, N.; Bucatariu, C.; Magid, J. Addressing food waste reduction in Denmark. Food Policy 2014, 49, 294-301. [CrossRef]

13. Visschers, V.H.M.; Wickli, N.; Siegrist, M. Sorting out food waste behaviour: A survey on the motivators and barriers of self-reported amounts of food waste in households. J. Environ. Psychol. 2016, 45, 66-78. [CrossRef]

14. Quested, T.E.; Marsh, E.; Stunell, D.; Parry, A.D. Spaghetti soup: The complex world of food waste behaviours. Resour. Conserv. Recycl. 2013, 79, 43-51. [CrossRef]

15. Thyberg, K.L.; Tonjes, D.J. Drivers of food waste and their implications for sustainable policy development. Resour. Conserv. Recycl. 2016, 106, 110-123. [CrossRef]

16. Jörissen, J.; Priefer, C.; Bräutigam, K.-R. Food waste generation at household level: Results of a survey among employees of two European research centers in Italy and Germany. Sustainability 2015, 7, 2695-2715. [CrossRef] 
17. Bernstad, A. Household food waste separation behaviour and the importance of convenience. Waste Manag. 2014, 34, 1317-1323. [CrossRef] [PubMed]

18. Hebrok, M.; Boks, C. Household food waste: Drivers and potential intervention points for design-An extensive review. J. Clean. Prod. 2017, 151, 380-392. [CrossRef]

19. Girotto, F.; Alibardi, L.; Cossu, R. Food waste generation and industrial uses: A review. Waste Manag. 2015, 45, 32-41. [CrossRef] [PubMed]

20. Bernstad, A.; la Cour Jensen, J. A life cycle approach to the management of household waste-A Swedish full-scale study. Waste Manag. 2011, 31, 1879-1896. [CrossRef] [PubMed]

21. Thyberg, K.L.; Tonjes, D.J. The environmental impacts of alternative food waste treatment technologies in the U.S. J. Clean. Prod. 2017, 158, 101-108. [CrossRef]

22. Kim, M.-H.; Kim, J.-W. Comparison through a LCA evaluation analysis of food waste disposal options from the perspective of global warming and resource recovery. Sci. Total Environ. 2010, 408, 3998-4006. [CrossRef] [PubMed]

23. Saraiva Schott, A.B.S.; Andersson, T. Food waste minimization from a life-cycle perspective. J. Environ. Manag. 2015, 147, 219-226. [CrossRef] [PubMed]

24. Lebersorger, S.; Schneider, F. Discussion on the methodology for determining food waste in household waste composition studies. Waste Manag. 2011, 31, 1924-1933. [CrossRef] [PubMed]

25. Essonanawe Edjabou, M.; Petersen, C.; Scheutz, C.; Fruergaard Astrup, T. Food waste from Danish households: Generation and composition. Waste Manag. 2016, 52, 256-268. [CrossRef] [PubMed]

26. Waste and Resources Action Programme (WRAP). Methods Used for Household Food and Drink Waste in the UK 2012. Available online: http:/ / www.wrap.org.uk/sites/files/wrap/Methods\%20Annex\%20Report \% 20v2.pdf (accessed on 26 February 2018).

27. Department for Environment, Food and Rural Affairs (DEFRA). Food Statistics Pocketbook 2012; DEFRA: London, UK, 2012.

28. Papargyropoulou, E.; Lozano, R.; Steinberger, J.K.; Wright, N.; bin Ujang, Z. The food waste hierarchy as a framework for the management of food surplus and food waste. J. Clean. Prod. 2014, 76, 106-115. [CrossRef]

29. Steg, L.; Vlek, C. Encouraging pro-environmental behaviour: An integrative review and research agenda. J. Environ. Psychol. 2009, 29, 309-317. [CrossRef]

30. 2011 Census Snapshot for Eastleigh Borough. Available online: http://www.eastleigh.gov.uk//pdf/ Census\%20Snapshot\%20-\%20Eastleigh\%20Borough\%20-\%2020130314a.pdf (accessed on 26 February 2014).

31. Underwood, A.J. Beyond BACI: The detection of environmental impacts on populations in the real, but variable, world. J. Exp. Mar. Biol. Ecol. 1992, 161, 145-178. [CrossRef]

32. Waste and Resources Action Programme (WRAP). Love Food, Hate Waste. Available online: http:/ / www. lovefoodhatewaste.com (accessed on 1 August 2013).

33. Dahlén, L.; Lagerkvist, A. Methods for household waste composition studies. Waste Manag. 2008, 28, 1100-1112. [CrossRef] [PubMed]

34. Lyas, J.K.; Shaw, P.J.; van Vugt, M. Provision of feedback to promote householders' use of a recycling scheme-A social dilemma approach. J. Solid Waste Technol. Manag. 2004, 30, 7-18.

35. Read, A.D. "A weekly doorstop recycling collection, I had no idea we could" Overcoming the local barriers to participation. Resour. Conserv. Recycl. 1999, 26, 217-249. [CrossRef]

36. Shaw, P.J.; Maynard, S.J. The potential of financial incentives to enhance householders' kerbside recycling behaviour. Waste Manag. 2008, 28, 1732-1741. [CrossRef] [PubMed]

37. Bovill, D. Patterns of Pay: Estimates from the Annual Survey of Hours and Earnings, UK, 1997 to 2013; Office for National Statistics: London, UK, 2014.

38. Noehammer, H.C.; Byer, P.H. Effect of design variables on participation in residential curbside recycling programs. Waste Manag. Res. 1997, 15, 407-427. [CrossRef]

39. Schultz, P.W.; Oskamp, S.; Mainieri, T. Who recycles and when? A review of personal and situational factors. J. Environ. Psychol. 1995, 15, 105-121.

40. Stancu, V.; Haugaard, P.; Lähteenmäki, L. Determinants of consumer food waste behaviour: Two routes to food waste. Appetite 2016, 96, 7-17. [CrossRef] [PubMed]

41. Graham-Rowe, E.; Jessop, D.C.; Sparks, P. Predicting household food waste reduction using an extended theory of planned behaviour. Resour. Conserv. Recycl. 2015, 101, 194-202. [CrossRef] 
42. Thomas, C.; Sharp, V. Understanding the normalisation of recycling behaviour and its implications for other pro-environmental behaviours: A review of social norms and recycling. Resour. Conserv. Recycl. 2013, 79, 11-20. [CrossRef]

43. Shaw, P.J.; Smith, M.M. Recipes for the prevention of bread waste? In Proceedings of the Third Symposium on Urban Mining, Bergamo, Italy, 23-25 May 2016.

44. Yamakawa, H.; Williams, I.D.; Shaw, P.J.; Watanabe, K. Food waste prevention: Lessons from the Love Food, Hate Waste campaign in the UK. In Proceedings of the 16th International Waste Management and Landfill Symposium, S. Margherita di Pula, Sardinia, Italy, 2-6 October 2017.

45. Barr, S. Strategies for sustainability: Citizens and responsible environmental behaviour. Area 2003, 35, 227-240. [CrossRef]

(C) 2018 by the authors. Licensee MDPI, Basel, Switzerland. This article is an open access article distributed under the terms and conditions of the Creative Commons Attribution (CC BY) license (http:/ / creativecommons.org/licenses/by/4.0/). 